\title{
A transferência fonético-fonológica L2 (francês) - L3 (inglês): um estudo de caso
}

L2 (French)- L3 (English) phonic-phonological transfer: a case study

\author{
Cintia Avila Blank \\ $\mathrm{UCPel}$ \\ Márcia Cristina Zimmer \\ $\mathrm{UCPel}$
}

\section{Abstract}

In the field of second language acquisition, one can easily find studies on the relationship between the L1 and the L2. However, investigations focusing on the influence of previously learned languages (both the L1 and the L2) over the acquisition of a third language are very scarce. This gap motivated a case study on the L2-L3 phonic-phonological transfer in which it was investigated whether the vowels produced in the participants' L3 (English) would be assimilated towards the L2 (French) or L1 (Brazilian Portuguese) spectral (F1 and F2) and durational characteristics. The data, obtained via naming tasks performed in the three languages spoken by the subject, were analyzed acoustically with Praat (version 4.4.2.2). The results regarding the acoustic vowel analysis suggest the creation of hybrid phonetic categories between the L1 and L2, which were assimilated by the participants' L3 vowels.

Keywords

Multilingualism; L2-L3 phonic-phonological transfer; vowel assimilation. 


\section{Resumo}

Ao observar o foco dos estudos em aquisição de língua estrangeira, não é raro encontrar trabalhos sobre as relações entre a língua materna (L1) e a língua estrangeira (L2). Contudo, investigações acerca de como o conhecimento das línguas previamente aprendidas (tanto a L1 como a L2) podem influenciar a aquisição de uma terceira língua (L3) são escassas. Essa lacuna motivou um estudo de caso sobre a transferência fonético-fonológica em que se investigou se a assimilação vocálica na L3 (inglês) ocorreria em direção às características vocálicas (F1, F2 e duração) da L1 (português) ou da L2 (francês) do participante. Os dados, obtidos através de tarefas de leitura oral nas três línguas, foram analisados acusticamente com o programa Praat. Discutidos a partir do conexionismo, os resultados da análise acústica apontam para a criação, nas vogais da L3, de categorias fonéticas híbridas entre a L1 e a L2.

\section{Palavras-chave}

Multilinguismo; transferência fonético-fonológica L2-L3; assimilação vocálica. 


\section{Introdução}

T númeras são as pesquisas focadas na investigação da natureza da transferência da L1 para a L2. ${ }^{1}$ Parecem, porém, ser escassos os trabalhos que contemplam questões concernentes à transferência de padrões linguísticos entre duas ou mais línguas estrangeiras, a despeito da crescente atenção que alguns países, como os do continente europeu, vêm conferindo ao multilinguismo. Dessa forma, faz-se necessário discutir a suposição ainda muito pouco investigada de que a última língua adquirida por um aprendiz exerceria uma maior influência sobre a próxima a ser aprendida, e aí se percebe uma lacuna importante a ser preenchida na pesquisa psicolinguística, sobretudo em se considerando um arcabouço teórico conexionista. Diante desses fatos, e também do fato de a língua portuguesa não ter sido incluída, até o presente momento, nos estudos disponíveis no campo de aquisição de L3, pretende-se, neste artigo, apresentar um estudo de caso que analisou o processo de transferência fonético-fonológica ${ }^{2}$ envolvendo o recurso à assimilação vocálica nas produções orais de um sujeito falante de português como L1, de francês como L2, e de inglês como L3. Os dados da pesquisa, obtidos através da gravação de tarefas de leitura oral nas três línguas faladas pelo sujeito, foram analisados com o auxílio do programa Praat (versão 4.4.2.2), que forneceu as medidas acústicas (F1, F2 e duração) $)^{3}$ das vogais analisadas.

Para apresentar este estudo, o trabalho ora apresentado encontra-se dividido em três seções principais: uma destinada a revisar os pressupostos teóricos pertinentes para embasar os resultados a serem discutidos; outra centrada na explicitação da metodologia empregada no estudo; e uma última seção, destinada a discutir os resultados encontrados, de acordo com a perspectiva conexionista de aquisição da linguagem. 


\section{Fundamentação Teórica}

\subsection{Conexionismo e aquisição da linguagem}

O conexionismo, paradigma de investigação que destaca a importância de fatores biológicos e ambientais para o desenvolvimento da cognição, considera que todo tipo de informação é processado no cérebro através das redes neuroniais. Os neurônios, células nervosas que compõem essas redes, comunicam-se entre si, transmitindo impulsos elétricos. Conforme mostram os estudos neurocognitivos, as redes neuroniais são modificadas de acordo com a atividade sináptica estabelecida entre os neurônios. Quando determinados subconjuntos de neurônios são mais estimulados do que outros, esses padrões de atividades elétricas mais fortes são impressos com mais intensidade, mudando o peso entre as conexões neuroniais (MCCLELLAND et al., 1995). Essa atividade seria, no nível da microcognição, responsável pela base da formação da memória e do aprendizado. Como as sinapses acontecem simultaneamente em diversas partes do cérebro, de forma gradual e contínua, como explicam Seidenberg; Mcclelland; e Zevin (2006), o conexionismo denomina esse funcionamento PDP (Processamento Distribuído em Paralelo). Dessa forma, o conexionismo postula que as diversas regiões do cérebro trabalham simultaneamente para produzir cognição (RUMELHART; MCCLELLAND, 1986).

No que tange especificamente ao campo de aquisição da linguagem, o conexionismo o entende como a aquisição de qualquer outra capacidade cognitiva humana. Dessa forma, acredita-se na existência de uma relação intrínseca entre o desenvolvimento da linguagem e o desenvolvimento de outras capacidades cognitivas humanas, sendo, dessa forma, a interação entre esses processos o fator desencadeador da aprendizagem de uma dada língua. Por entender a linguagem em meio a esse processo de interação, o conexionismo segue uma orientação emergentista de aquisição da linguagem (BATES, 1999; N. ELLIS, no prelo), dispensando questões consideradas centrais pelo paradigma simbólico, como a proposição de mecanismos inatos para que a linguagem se estabeleça no indivíduo (CHOMSKY, 1965).

O conexionismo também vê a aquisição da linguagem em termos de desempenho - e não de competência, como postulou Chomsky (1965) -, o que torna possível que as regularidades linguísticas sejam extraídas através de fatores estatísticos e probabilísticos presentes num determinado input linguístico. Assim, 
parece correto afirmar que a experiência do indivíduo com a língua desponta como fator primordial para a sua aquisição. Cumpre ressaltar, por fim, que o escopo do conexionismo recai sobre o processo de aquisição da linguagem, já que há uma preocupação em descrever as etapas dessa aquisição, e não somente o seu estado final, posição assumida pela vertente simbólica.

Com essa breve apresentação dos pressupostos defendidos pelo paradigma conexionista em relação à aquisição da linguagem, pode-se passar para a próxima seção, destinada a apresentar alguns conceitos desenvolvidos sobre a aquisição de uma L3.

\subsection{A aquisição da L3}

Uma das primeiras pesquisas a ganhar vulto no campo de aquisição de L3 foi a de Ringbom (1987), que observou, num grupo de finlandeses falantes de sueco como L2 e aprendizes de inglês como L3, uma preferência relevante em recorrer ao sueco, sua $\mathrm{L} 2$, e não ao finlandês, sua L1, no momento de produção da fala eminglês (L3). Após o desenvolvimento de mais pesquisas que continuavam apontando a influência da L2 na aprendizagem da L3, teve início a construção de um marco teórico para a aquisição de L3. Com isso, puderam-se elencar alguns fatores que pareciam contribuir de maneira expressiva para que a transferência interlinguística se estabelecesse no sentido L2-L3.

O primeiro fator relacionado aqui, considerado por vários pesquisadores como o decisivo para que a $\mathrm{L} 2$ influencie com mais peso durante a aprendizagem de L3, é a distância tipológica observada entre as línguas (HAMMARBERG, 2001; CENOZ, 2000). Para Cenoz (op.cit), esse fator pode determinar a escolha de uma certa língua como fonte principal de influência. Nesse sentido, a influência da L2 será mais notada se essa língua for tipologicamente mais próxima da L3 do que a L1. Kellerman (1983) foi um dos primeiros a destacar o papel da tipologia como fator relevante na transferência L2-L3. No entanto, sua abordagem, denominada "psicotipologia", destacava o papel do aprendiz para a identificação da distância entre as línguas. Para o autor, muitas vezes a percepção do aprendiz não corresponde, necessariamente, à distância tipológica real. Assim, o surgimento de uma percepção psicotipológicaé visto como fruto do desenvolvimento da competência metacognitiva e da consciência metalinguística do aprendiz. Sikogukira (1993) acredita que o estilo e o ambiente de aprendizagem podem estar relacionados com esse efeito de "similaridade psicológica" que o aprendiz 
credita a duas línguas, pois, segundo o autor, se duas línguas forem aprendidas da mesma forma, em situações semelhantes e com base num mesmo método, elas influenciarão marcadamente uma à outra.

O segundo fator apontado como significativo para o estabelecimento da transferência L2-L3 é o grau de proficiência do aprendiz na sua L2. De acordo com Hammarberg (op. cit.), um nível elevado de proficiência na $L 2$ pode favorecer a influência dessa língua sobre a L3, sobretudo se a L2 do aprendiz tiver sido adquirida e utilizada num ambiente natural, e não num contexto formal de aprendizagem. No entanto, observa-se que, à medida que o nível de proficiência na L3 vai aumentando, o aprendiz não encontra mais tanta necessidade de recorrer a sua L2 para desempenhar seus objetivos comunicativos na L3.

O efeito de recência também é citado como um fator relevante da transferência L2-L3. Hammarberg (op. cit.) é assertivo quanto a serem as influências de uma L2 mais notadas na produção de uma L3 se aquela língua tiver sido usada recentemente. Como a L2 recebe uma grande demanda de ativação à medida que se vai desenvolvendo, ela acaba ficando mais acessível ao aprendiz de L3. O efeito de uso recente, segundo o autor, pode ser propiciado por qualquer contato com a L2, seja ele evidenciado em termos de produção, seja de percepção.

As transferências L2-L3 podem ser desencadeadas também pelo status que o aprendiz atribui à L2. Esse status é explicado por Williams e Hammarberg (1998) com base em dois fatores: primeiro, pela possibilidade de haver mecanismos diferentes de aquisição tanto para a L1 como para a L2. Dessa forma, no momento do uso de uma L3, o mesmo tipo de mecanismo ativado pela L2 será ativado para aquela língua, excluindo a $\mathrm{L} 1$ desse processo. Segundo, pela necessidade que tem o aprendiz de bloquear o acesso à L1, já que ela tem um status de língua não estrangeira. $\mathrm{O}$ aprendiz apoia-se na $\mathrm{L} 2$, então, por ela ter um status de língua estrangeira em oposição à L1. Nessa perspectiva, há uma tentativa do aprendiz de L3 em contornar os efeitos da L1, língua materna, com o uso mais evidente da sua L2.

Cabe fazer referência, também, ao modelo de aquisição de L3 desenvolvido por de Bot (2004). Em sua teoria denominada Modelo de Processamento Multilíngue (The Multilingual Processing Model), de Bot faz uma consideração que se mostra bastante relevante para esta pesquisa, já que o autor prediz uma competição, no nível fonológico, entre as formas semelhantes das línguas do trilíngue. 
Levando-se em consideração os principais achados do campo de investigação da $\mathrm{L} 3$, pode-se passar para a explicação do processo de transferência fonético-fonológica envolvendo a L1 e a L2 .

\subsection{A transferência fonético-fonológica da $L 1$ para a $L 2$}

No momento em que começa a adquirir um novo sistema linguístico, o aprendiz de L2 costuma deparar-se com inúmeras dificuldades para superar os efeitos do conhecimento fonético-fonológico da sua L1 sobre a fala incipiente em L2, o que parece estar relacionado com uma forte tendência em haver um certo grau de transferência entre esses dois sistemas distintos.

De acordo com o Modelo de Aprendizagem da Fala (Speech Learning Model), desenvolvido por Flege (1995), os processos e mecanismos que as crianças utilizam quando estabilizam o sistema de sons da L1 permanecem intactos durante toda a vida do indivíduo, mantendo-se acessíveis inclusive quando da aprendizagem de uma L2. Contudo, isso não implica dizer que os bilíngues tardios apresentarão, necessariamente, proficiência na L2 semelhante àquela demonstrada pelos bilíngues precoces, nem tampouco que sua proficiência possa ser comparada com a de um falante nativo. A principal razão para isso reside no fato de os aprendizes tardios de L2 continuarem a fazer uso maciço da sua L1, o que, provavelmente, acaba influenciando em seus desempenhos na L2. Conforme Flege (2002), o sistema fonético da L1 desenvolve-se vagarosamente durante a infância, num processo que culmina com a chegada da adolescência. Assim, à medida que as categorias fonéticas da L1 se desenvolvem, mais chances terão de assimilar perceptualmente as vogais e consoantes presentes na L2. Isso porque se acredita que os sistemas de sons da L1 e da L2 existem num espaço fonológico comum e, dessa forma, passam a influenciar um ao outro.

Mesmo tendo disponíveis as mesmas condições que uma criança quando estabiliza o sistema de sons da sua L1, o aprendiz tardio de L2, conforme admite Flege (2002), nem sempre cria novas categorias de sons. A tendência é que o aprendiz tardio identifique uma vogal ou consoante da L2 como sendo similar a uma categoria já estabilizada de vogal ou consoante da L1. Tal ocorrência é explicada com base na postulação de um mecanismo denominado "categorização por equivalência", que tende a prevenir a criação de novas categorias de sons para a L2, igualando-os aos da L1. No entanto, o funcionamento desse mecanismo depende, em grande parte, da distância fonética percebida entre os 
sons da L2 e da L1. A hipótese defendida pelo Modelo de Aprendizagem da fala assevera que, quanto mais distantes foneticamente os sons da L1 e da L2 forem percebidos, mais facilmente serão criadas novas categorias para os sons da L2.

Com base na relação de proximidade ou distância entre as categorias de sons da L1 e da L2, Flege (2002) propõe dois mecanismos específicos através dos quais os subsistemas fonéticos dessas duas línguas podem interagir: o mecanismo de assimilação categórica e o mecanismo de dissimilação categórica. Espera-se que os sistemas fonéticos da L1 e da L2 interajam por meio do mecanismo de assimilação categórica quando houver um bloqueio na formação de novas categorias. Dessa forma, os aprendizes de L2 podem, inicialmente, produzir os sons da fala da L2 como se estes fossem correspondentes aos sons da fala da L1; assim, o aprendiz de L2 parece impelido a julgar, indefinidamente, as instâncias de uma categoria da L2 como semelhantes a uma categoria pertencente à L1, por não perceber nenhuma diferença entre a produção de ambas. Nesse caso, não há nenhuma modificação na produção dos sons. Em contrapartida, espera-se que os sistemas fonéticos interajam através do mecanismo de dissimilação categórica se os sons da L2 diferirem perceptualmente dos sons da L1. Nesse processo, é esperada a ocorrência da estabilização de uma nova categoria de som para a L2.

Cumpre ressaltar que, mesmo havendo um bloqueio de categoria, isso não impede que a aprendizagem fonética se estabeleça, pelo menos para os bilíngues tardios que têm a sensibilidade de perceber as diferenças fonéticas subcategóricas entre a L1 e a L2. Quando não houver a formação de uma nova categoria, no entanto, haverá uma tendência dos bilíngues a desenvolverem uma categoria "híbrida" da L1 e da L2. A referida categoria assumirá, então, as propriedades dos sons da fala da L1 e da L2 que são distintos foneticamente, mas percebidos como semelhantes. Com base nessa categoria fundida, será identificado e produzido o som da fala da L1 e da L2 equivalente em termos de percepção.

A próxima seção tratará da ocorrência da assimilação vocálica como um processo de transferência fonético-fonológica.

\subsection{A assimilação vocálica e a transferência fonético-fonológica}

Sabe-se que durante a fala em L2 vários processos de transferência podem ocorrer, dependendo das diferenças nas correspondências fonéticofonológicas observadas entre os sistemas linguísticos em jogo. Um desses 
processos, a assimilação vocálica, tem sua importância destacada pelo fato de todas as palavras conterem vogais e, caso essas vogais tenham sua pronúncia deturpada, essa pronúncia não equivalente à padrão da língua nativa pode levar não somente à produção de um sotaque estrangeiro, mas também a possíveis falhas na comunicação.

Zimmer (2004) conceitua a assimilação vocálica como um tipo de assimilação do conhecimento fonético-fonológico da L1 para a L2, que pode ocorrer em relação a características espectrais, acarretando uma mudança na qualidade vocálica, bem como a características ligadas ao tempo de duração das vogais. Fatores relacionados à mudança da qualidade vocálica costumam ser desprezados, já que existe uma grande variação desse aspecto entre os próprios falantes nativos do inglês, dependendo da região onde vivem ou de seu país de origem (JENKINS, 2001; WALKER, 2001). A diferença na duração das vogais do inglês, por outro lado, está presente em todos os dialetos, e as vogais longas do inglês são consideradas longas em relação a praticamente todas as vogais das línguas conhecidas (ZIMMER, 2004). Todavia, Zimmer (2004) enfatiza a necessidade de não se negligenciarem os aspectos relacionados à qualidade das vogais, visto que tal característica também pode acarretar mudanças que alteram distinções lexicais.

Exemplos de transferência interlinguística resultando no processo de assimilação vocálica são fornecidos por Zimmer et al. (no prelo). Em seu livro, que faz uma apresentação detalhada de vários processos de transferência produzidos por brasileiros aprendizes de inglês como L2, os autores citam o caso das vogais [i] e [I] do inglês, que costumam ter sua pronúncia neutralizada pela produção do [i] do português brasileiro, assim como as vogais $[\mathrm{u}] \mathrm{e}[\mathrm{U}]$ do inglês, que também apresentam sua pronúncia neutralizada pelo $[\mathrm{u}]$ do português.

Após essas exposições preliminares a respeito do processo de assimilação vocálica envolvendo a L1 e a L2, pode-se passar a explicá-lo em função de três sistemas linguísticos, tendo como base uma abordagem conexionista.

\subsection{A assimilação vocálica e a transferência fonético-fonológica L2-L3: uma problematização conexionista}

A fim de entender o motivo pelo qual as transferências fonéticofonológicas que geram a assimilação vocálica na $\mathrm{L} 3$ poderiam ser originadas na L2, e não na L1, apesar de esta língua ser a mais consolidada, pode-se recorrer 
a alguns pressupostos elencados pelas teorias de L3, que podem ser mobilizados de forma a servir de base para a proposição de uma visão de cunho conexionista para esse processo.

O que a teoria de L3 chama de efeito de recência, muito relacionado à noção de conhecimento prévio estipulada pelo conexionismo, pode favorecer a ocorrência de transferências no sentido L2-L3, já que a L2 configura-se no conhecimento linguístico mais recente a passar por um processo de consolidação nos sistemas de memória. Dessa forma, o conhecimento fonético-fonológico da L2 tende a ser transferido com mais frequência durante o uso da L3, o que pode afetar a ativação do conhecimento das vogais, gerando o processo de assimilação vocálica entre a L2 e a L3.

Ao utilizar a L3, o aprendiz pode ativar o conhecimento fonético-fonológico para uma vogal, por exemplo, de acordo com as representações mais entrincheiradas ${ }^{4}$ que ele conhece para ela, seja a da L1 ou a da L2. Para que o conhecimento de uma dessas duas línguas seja o escolhido durante o processo de competição, o aprendiz pode apoiar-se em suas impressões a respeito do grau da proximidade que atribui a elas em relação à L3, conferindo talvez à L2 uma maior semelhança pelo fato de ela possuir um status de língua não materna. Assim, a L2 pode transferir para a L3 o conhecimento fonético-fonológico de suas vogais mesmo que sua correspondência não seja a mais semelhante, o que está relacionado com a noção de psicotipologia, responsável por ativar esses efeitos de semelhança.

É digno de referência, igualmente, que autores como Flege (2002) e MacWhinney (2002) indicam que o grau de semelhança entre as línguas tem uma grande responsabilidade para a ocorrência de transferências. Cabe frisar, entretanto, que as transferências surgidas pela identificação de semelhanças entre as línguas podem apresentar não apenas efeitos facilitadores para a aprendizagem, mas também alguns obstáculos. Segundo Flege (2002), se houver uma identificação contínua dos sons da L2 com instâncias de fonemas e alofones da L1 - gerada por um alto grau de semelhança entre os sistemas sonoros -, a formação de novas categorias de contrastes será bloqueada. Entretanto, se for notada uma diferença muito grande entre os padrões sonoros de ambas as línguas, é esperada uma diferenciação entre essas produções, com a criação de novas categorias de contraste. A não criação de uma categoria de contraste na L3, por exemplo, pode implicar o recurso à assimilação vocálica durante uma tarefa de leitura nessa língua, caracterizando a ocorrência da transferência 
fonético-fonológica envolvendo a participação da L2 e da L1, ou de uma dessas línguas de maneira mais destacada.

É importante referir, já que se está seguindo uma noção de aprendizagem conexionista, que a aprendizagem de L3 pode sofrer os efeitos tanto da transferência de padrões da L2 como da L1, já que não se pode destituir um sistema linguístico do processo de aquisição de um novo (FLEGE, 2002). Acredita-se, no entanto, que a influência da $\mathrm{L} 2$ - ou da $\mathrm{L} 1$ - sobre a $\mathrm{L} 3$ pode ser diminuída através de uma exposição adequada ao input da L3, uma vez que as capacidades cognitivas necessárias para a aquisição dos sons da fala perduram por toda a vida do aprendiz. Dessa forma, à medida que o nível de proficiência em L3 do aprendiz vai-se desenvolvendo, e à medida que o conhecimento fonético-fonológico dessa língua vai sendo consolidado, é possível que categorias de sons mais próximas dessa língua, e mais distantes daquelas conhecidas para a L1 e para a L2, sejam criadas. Não se espera, com isso, que a influência das correspondências grafêmicas dos demais sistemas fonético-fonológicos seja bloqueada, visto que não há possibilidade de separação entre eles, mas sim que haja o desenvolvimento de categorias mais equivalentes às da L3, ou mesmo híbridas entre as três línguas, assim como é proposto para a L2 (FLEGE, 2002).

Com a apresentação dos pressupostos teóricos que servem como norte para o desenvolvimento desta pesquisa, pode-se passar para a apresentação da metodologia aqui utilizada.

\section{Pesquisa empírica}

Em consonância com a revisão da literatura, esta pesquisa tem como objetivo geral investigar o processo de transferência fonético-fonológica do francês (L2) para o inglês norte-americano (L3) por um falante nativo do português brasileiro (L1). Partindo do objetivo geral formulado anteriormente, procurou-se analisar se a assimilação vocálica durante a tarefa de leitura oral de palavras em inglês (L3) ocorreria em direção às características (F1, F2 e duração) das vogais do português (L1) ou das vogais do francês (L2).

\subsection{Método}

A investigação empírica foi do tipo pesquisa de campo, realizada com um sujeito (estudo de caso) de forma transversal. Os dados foram coletados de um 
adulto (25 anos de idade) do sexo masculino, nativo do português brasileiro (natural de Pelotas/Rio Grande do Sul), falante de francês como L2 e de inglês como L3. Tanto a L2 quanto a L3 do participante foram aprendidas em cursos superiores de Letras (primeiro o participante formou-se em Francês para depois iniciar a Licenciatura em Inglês na Universidade Federal de Pelotas - UFPel). Esse sujeito apresentou proficiência alta em francês como L2 e intermediária em inglês como L3. Os critérios para a seleção do sujeito foram: a) o sujeito deveria ser falante nativo do português brasileiro; b) o sujeito deveria ser falante em nível avançado de francês como L2; c) o sujeito deveria ser falante em nível intermediário de inglês como L3; d) o sujeito deveria assinar um Termo de Consentimento Informado e responder a uma entrevista, que tinha por finalidade levantar dados relativos à idade, ao grau de instrução do informante, ao tempo de estudo em cada L2, e ao conhecimento de outras línguas estrangeiras que não as investigadas aqui; e, por fim, e) o sujeito deveria submeter-se a um teste de nivelamento tanto na L2 como na L3, para comprovar seu nível de proficiência (DALF, para o francês e TOEIC, para o inglês).

\subsection{Instrumentos da pesquisa}

Para a obtenção dos valores de F1, F2 e duração das vogais orais das três línguas faladas pelo sujeito investigado nesta pesquisa, foram utilizados três instrumentos de recodificação de palavras. O primeiro, adaptado de Zimmer (2004), contou com um total de 14 palavras da língua inglesa; o segundo, adaptado de Jared e Kroll (2001), com um total de 12 palavras da língua francesa; e, o terceiro, adaptado de Zimmer e Bion (2007), com 28 palavras da língua portuguesa. ${ }^{5}$ As palavras nas três línguas apresentadas ao sujeito foram vinculadas a frases-veículo (say xxx, le dernier mot est xxx, a última palavra é $x x x$ ), e cada frase-veículo foi disposta cinco vezes de forma aleatória durante a apresentação em arquivo do tipo powerpoint.

\subsection{Levantamento e computação dos dados}

As palavras recodificadas pelo sujeito, tendo como base os testes adaptados de Zimmer (2004), Zimmer e Bion (2007) e Jared e Kroll (2001), foram analisadas qualitativamente através do programa Praat, e quantitativamente através do cálculo das distâncias euclidianas entre os pares de vogais. As vogais 
das três línguas analisadas estatisticamente receberam um símbolo especial, que posteriormente foi trocado para o símbolo fonético correspondente (conforme o Alfabeto Fonético Internacional - IPA). Com base no levantamento das vogais que figuram neste estudo para cada língua, estabeleceram-se relações de comparação entre as vogais do português e do inglês e do francês e do inglês. Abaixo, seguem os pares de vogais cotejados entre duas línguas, com os símbolos utilizados na análise estatística e suas correspondências de acordo com o Alfabeto Fonético Internacional (QUADRO 1).

\section{QUADRO 1}

Pares de vogais comparados entre as línguas

\begin{tabular}{cc|cc}
\hline $\begin{array}{c}\text { Vogais comparadas entre } \\
\text { o português e o inglês (P-I) }\end{array}$ & \multicolumn{2}{c}{$\begin{array}{c}\text { Vogais comparadas entre } \\
\text { o francês e o inglês (F-I) }\end{array}$} \\
\hline P-I & P-I & F-I & F-I \\
\hline E-@ & $\varepsilon-æ$ & E-@ & $\varepsilon-æ$ \\
E-E & $\varepsilon-\varepsilon$ & E-E & $\varepsilon-\varepsilon$ \\
i-i & i-i & i-i & i-i \\
i-I & i-I & i-I & i-I \\
u-u & u-u & u-u & u-u \\
u-U & u-U & u-U & u-U \\
oh-oh & o- $-\mathrm{u}$ & oh-oh & $0-\mathrm{J}$ \\
\hline
\end{tabular}

\section{Resultados e discussão}

Nesta seção, os dados coletados com o propósito de testar o objetivo traçado nesta pesquisa serão apresentados e discutidos, com base numa análise qualitativa e quantitativa.

\subsection{Descrição dos resultados}

Para que se possa visualizar as distâncias euclidianas primeiramente para F1 e F2 entre os pares de vogais analisados neste artigo, pode-se observar os dados dos quadros 2 e 3 . O quadro a seguir (QUADRO 2) apresenta a comparação das distâncias euclidianas para F1 e F2 dos pares de vogais do francês e do inglês. 
QUADRO2

Distâncias euclidianas para F1 e F2 das vogais do francês e do inglês produzidas pelo sujeito

\begin{tabular}{l|ccccc}
\hline \multirow{2}{*}{ Distâncias } & \multicolumn{3}{|c}{ F1 } & \multicolumn{2}{c}{ F2 } \\
& $\begin{array}{c}\text { Pares } \\
\text { de vogais }\end{array}$ & $\begin{array}{c}\text { Dist. } \\
\text { Euclidiana }\end{array}$ & $\begin{array}{c}\text { Dist. } \\
\text { Padronizada }\end{array}$ & $\begin{array}{c}\text { Dist. } \\
\text { Euclidiana }\end{array}$ & $\begin{array}{c}\text { Dist } \\
\text { Padronizada }\end{array}$ \\
\hline & $\varepsilon-æ$ & 65,47 & $10,1 \%$ & 139,53 & $7,3 \%$ \\
& $\varepsilon-\varepsilon$ & 66,67 & $10,3 \%$ & 207,73 & $11,3 \%$ \\
& $\mathrm{i}-\mathrm{i}$ & 15,60 & $5,7 \%$ & 261,30 & $12,0 \%$ \\
& $\mathrm{i}-\mathrm{I}$ & 48,78 & $15,8 \%$ & 344,50 & $15,2 \%$ \\
& $\mathrm{u}-\mathrm{u}$ & 1,60 & $0,5 \%$ & 589,00 & $75,9 \%$ \\
& $\mathrm{u}-\mathrm{U}$ & 35,00 & $11,3 \%$ & 297,00 & $27,8 \%$ \\
& o- - Inglês & 4,70 & $0,8 \%$ & 0,60 & $0,1 \%$ \\
\hline
\end{tabular}

Com a apresentação das distâncias euclidianas para F1 e F2 entre os pares de vogais do francês e do inglês, passa-se para a visualização dos valores obtidos para a distância euclidiana entre os pares de vogais do português e do inglês (QUADRO 3).

$$
\text { QUADRO3 }
$$

Distâncias euclidianas para F1 e F2 das vogais do português e do inglês produzidas pelo sujeito

\begin{tabular}{l|ccccc}
\hline \multirow{2}{*}{ Distâncias } & \multicolumn{3}{|c}{$\mathrm{F} 1$} & \multicolumn{2}{c}{$\mathrm{F} 2$} \\
& $\begin{array}{c}\text { Pares } \\
\text { de vogais }\end{array}$ & $\begin{array}{c}\text { Dist. } \\
\text { Euclidiana }\end{array}$ & $\begin{array}{c}\text { Dist. } \\
\text { Padronizada }\end{array}$ & $\begin{array}{c}\text { Dist. } \\
\text { Euclidiana }\end{array}$ & $\begin{array}{c}\text { Dist } \\
\text { Pradronizada }\end{array}$ \\
\hline \multirow{5}{*}{ Frâs - Inglês } & $\varepsilon-æ$ & 29,80 & $4,6 \%$ & 50,70 & $2,8 \%$ \\
& $\varepsilon-\varepsilon$ & 31,00 & $4,8 \%$ & 118,90 & $6,5 \%$ \\
& $\mathrm{i}-\mathrm{i}$ & 16,20 & $5,9 \%$ & 55,20 & $2,5 \%$ \\
& $\mathrm{i}-\mathrm{I}$ & 16,98 & $5,5 \%$ & 138,40 & $6,1 \%$ \\
& $\mathrm{u}-\mathrm{u}$ & 20,80 & $6,0 \%$ & 473,25 & $61,0 \%$ \\
& $\mathrm{u}-\mathrm{U}$ & 15,80 & $5,1 \%$ & 181,25 & $17,0 \%$ \\
& $\mathrm{O}-\mathrm{O}$ & 4,47 & $0,7 \%$ & 135,33 & $12,2 \%$ \\
\hline
\end{tabular}

As distâncias entre os pares de vogais analisados apontam tendências de aproximação tanto do português em relação ao inglês, como também do francês em relação ao inglês. Para que se tenha uma ideia mais clara a respeito das 
comparações realizadas entre as línguas, os gráficos abaixo (FIG. 1 e 2) apresentam os valores obtidos tanto para $\mathrm{F} 1$ como para $\mathrm{F} 2$ para os pares de vogais do português e do inglês, e do francês e do inglês.

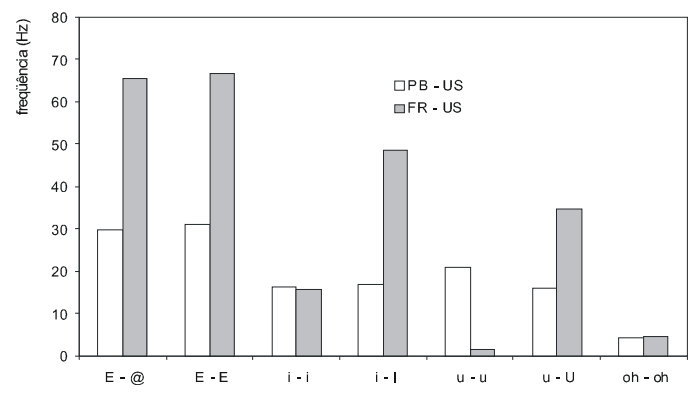

FIGURA 1 - Distâncias euclidianas (F1) entre português/inglês (PB-US) e entre francês/inglês (FR-US) $(E=\varepsilon, @=æ, i=i, I=I, u=u, U=U, o h=0)$

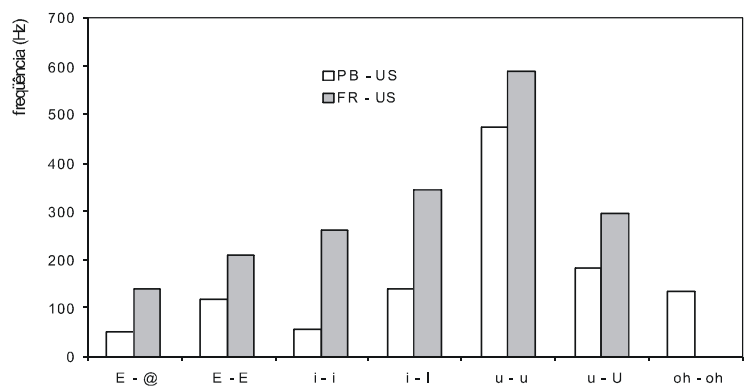

FIGURA 2 - Distâncias euclidianas (F2) entre português/inglês (PB-US) e entre francês/inglês (FR-US) $(E=\varepsilon, @=æ, i=i, I=I, u=u, U=U, o h=0)$

$\mathrm{Na}$ análise de $\mathrm{F} 1$, os pares /i/-/i/ e /u/-/u/ apresentaram as menores distâncias na comparação francês/inglês. Já na análise de F2, o par / ///つ/ foi o que apresentou uma distância expressivamente menor entre o francês e o inglês.

A distância euclidiana para os pares de vogais /i///I/, /u/-/u/, /ع/-/æ/ e $/ \varepsilon /-/ \varepsilon /$ foi menor para o português e para o inglês, tanto em altura quanto em anterioridade/posterioridade. Já para os pares /i/-/i/e /u/-/u/, embora a distância entre o francês e o inglês tenha sido menor no eixo vertical (F1) (francês/inglês: 
/i///i/ $=5,7 \%, / \mathrm{u} /-/ \mathrm{u} /=0,5 \%$; português/inglês: $/ \mathrm{i} / / \mathrm{i} /=5,9 \%, / \mathrm{u} /-/ \mathrm{u} /=6,0 \%$, o plano horizontal (F2) apresentou valores muito menores entre o português e o inglês (português/inglês: $/ \mathrm{i} /-\mathrm{i} /=2,5 \%, / \mathrm{u} /-/ \mathrm{u} /=61,0 \%$; francês/inglês: $/ \mathrm{i} /-\mathrm{i} /=12,0 \%$, $/ \mathrm{u} /-/ \mathrm{u} /=75,9 \%$ ). O par de vogais $/ \mathrm{o} / \mathrm{-} / \mathrm{/} /$, apesar de ter ficado numa mesma posição no eixo de $\mathrm{F} 2$ para o francês e o inglês, apresentou valores praticamente idênticos de distância para o eixo de F1 nas duas comparações entre línguas (português/inglês, francês/inglês). Com base na figura seguinte (FIG. 3), pode-se visualizar as vogais das três línguas comparadas no espaço acústico.

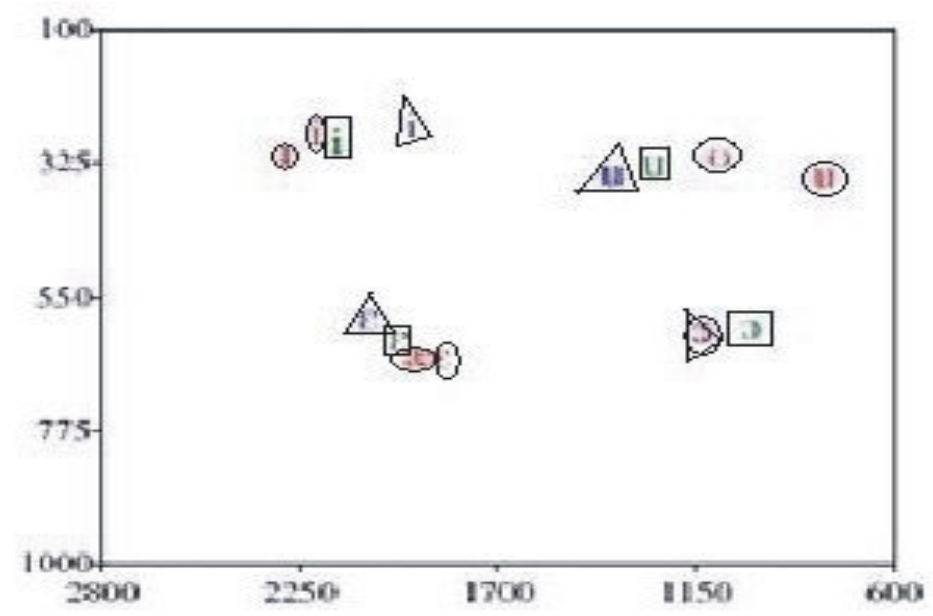

FIGURA 3 - Vogais das três línguas produzidas pelo sujeito (português, em quadrados; francês, em triângulos; e inglês, em círculos)

Apesar de o português ter-se aproximado em F1 e F2 para alguns pares de vogais, a comparação das distâncias euclidianas entre as três línguas deve ser interpretada com cautela, já que pares importantes, como /i/-/i/ e /u/-/u/, aproximaram-se mais na relação português/inglês em apenas uma das características em análise. Para que se tenha uma visão mais geral do posicionamento das vogais do sujeito no espaço acústico, mais uma última comparação será feita, considerando, além das três línguas aqui citadas, o posicionamento das vogais do inglês norte-americano descrito por Peterson e Barney (1952). 


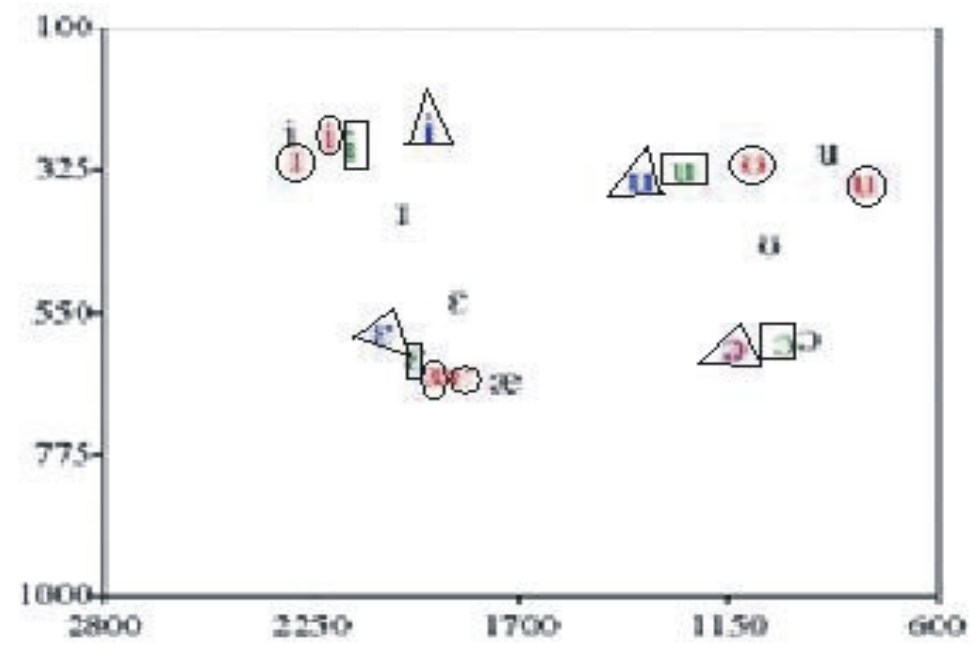

FIGURA 4 - Vogais das três línguas produzidas pelo sujeito (português, em quadrados; francês, em triângulos; e inglês, em círculos), e vogais do inglês padrão, sem marcação (PETERSON; BARNEY, 1952)

Numa análise geral da figura anterior, podem ser visualizados quatro grupos distintos envolvendo as vogais em estudo. Um grupo abarca as vogais $/ \mathrm{i} / \mathrm{e} / \mathrm{I} /$, outro as vogais /u/ e/u/, um terceiro as vogais /E/ e /æ/, e um último as vogais $/ \mathrm{s}$ produzidas pelo sujeito para as três línguas. Nota-se, porém, que as vogais $/ \mathrm{I} /, / \circlearrowleft / \mathrm{e} / \varepsilon /$ do inglês padrão ficaram bem destacadas das vogais produzidas pelo sujeito para os grupos de vogais /i/,/I/, /u/, / / / e/E/, respectivamente. A vogal $/ \mathrm{u} /$ produzida pelo sujeito para o inglês apresentou-se a uma posição de altura e de posterioridade muito próxima ao considerado padrão para essa língua, distanciando-se bastante das outras vogais aglomeradas nesse grupo, o que leva a pensar que o sujeito começa a criar uma categoria própria para essa vogal do inglês. Mesmo assim, cabe observar que as vogais /u/ do francês e do português produzidas pelo sujeito e a vogal /u/ do inglês padrão possuem uma altura muito semelhante. Assim sendo, o que parece indicar a criação de uma nova categoria para essa vogal é o fato de ela ser a única a estar mais posteriorizada, tal como o esperado para o inglês padrão.

Já para a vogal /ऽ/, é notável que o sujeito tenha conseguido produzi-la de modo diferente da vogal/u/ do inglês, realizando-a num espaço acústico mais anterior, assim como o esperado para essa vogal na língua inglesa padrão. No 
entanto, houve uma grande influência da vogal/u/ do português e do francês na sua colocação em termos de altura.

No grupo de vogais que concentra a produção das vogais/I/do inglês e/i/das três línguas, é possível notar uma ligeira distinção entre os pares de vogais /i/-/I/ produzidos pelo sujeito para a língua inglesa em termos de altura. Entretanto, como foi mencionado anteriormente, a vogal/I/ foi realizada mais anteriorizada do que o esperado. Considerando, então, a configuração apresentada para essa vogal, não se pode afirmar que uma categoria esteja sendo formada, mesmo porque sua colocação está muito próxima à das demais vogais produzidas pelo sujeito para esse grupo. Na análise da vogal/i/ produzida para o inglês, observa-se que ela não se apresentou num espaço vocálico mais definido, embora esteja próxima em relação à altura da vogal-alvo dessa língua. Cabe destacar, porém, que as vogais /i/ do português e do inglês também foram produzidas pelo sujeito a uma altura muito parecida. A vogal /i/ do francês foi a que mais se distanciou do agrupamento, destacando-se visivelmente no eixo de F2.

Quanto às vogais /æ/e/E/ dessa língua, não houve uma distinção adequada entre essas duas categorias, já que ambas as vogais apresentaram apenas uma diferenciação mínima em relação ao grau de anterioridade/posterioridade. Com a análise da figura 15, percebe-se que o sujeito produziu tais vogais mais baixas do que $o / \varepsilon /$ do português, do francês e do inglês padrão, e mais posteriores em relação ao /E/ do português e do francês.

Para o grupo das vogais / / distribuídas no espaço acústico, nota-se que as vogais do francês e do inglês do sujeito ficaram exatamente no mesmo local, tanto em termos de F1 quanto de F2. Contudo, é importante referir que a altura entre as vogais dos quatro sistemas analisados (considerando-se o inglês padrão) é muito semelhante. Dessa forma, as vogais do francês e do inglês do sujeito se destacam das demais (português do sujeito e inglês padrão) de maneira bastante visível por estarem mais anteriorizadas.

Tendo-se comparado a distância euclidiana para F1 e F2 dos pares de vogais das três línguas abarcadas por esta pesquisa, e tendo-se comparado essas distâncias com o posicionamento esperado para as vogais do inglês norteamericano padrão, cumpre examinar ainda a distância para duração encontrada entre os mesmos pares de vogais. Antes disso, porém, serão examinados os valores descritivos de duração para cada língua, de forma que se possam comparar as médias apresentadas para as vogais das três línguas (QUADRO 4). 
QUADRO4

Estatísticas descritivas para duração (em segundos) por língua

\begin{tabular}{|c|c|c|c|c|c|}
\hline & & \multicolumn{4}{|c|}{ Duração(s) } \\
\hline & Vogal & Mín & Máx & Média & Desvio-padrão \\
\hline \multirow[t]{7}{*}{ Inglês } & $æ$ & 0,0827 & 0,0922 & 0,0880 & 0,0047 \\
\hline & $\varepsilon$ & 0,1115 & 0,1265 & 0,1210 & 0,0058 \\
\hline & $\mathrm{i}$ & 0,0536 & 0,1338 & 0,0875 & 0,0277 \\
\hline & I & 0,0536 & 0,0926 & 0,0671 & 0,0125 \\
\hline & 0 & 0,0708 & 0,0879 & 0,0781 & 0,0064 \\
\hline & $\mathrm{u}$ & 0,0408 & 0,0708 & 0,0562 & 0,0113 \\
\hline & $U$ & 0,0521 & 0,0901 & 0,0708 & 0,0115 \\
\hline \multirow[t]{4}{*}{ Francês } & $\varepsilon$ & 0,0601 & 0,1029 & 0,0843 & 0,0130 \\
\hline & $\mathrm{i}$ & 0,0450 & 0,0718 & 0,0597 & 0,0087 \\
\hline & 0 & 0,0761 & 0,1126 & 0,0873 & 0,0128 \\
\hline & $\mathrm{u}$ & 0,0590 & 0,0772 & 0,0654 & 0,0078 \\
\hline \multirow[t]{4}{*}{ Português } & $\varepsilon$ & 0,0658 & 0,0874 & 0,0794 & 0,0095 \\
\hline & $\mathrm{i}$ & 0,0440 & 0,0791 & 0,0589 & 0,0152 \\
\hline & 0 & 0,0606 & 0,0764 & 0,0682 & 0,0079 \\
\hline & $\mathrm{u}$ & 0,0380 & 0,0595 & 0,0511 & 0,0094 \\
\hline
\end{tabular}

Observando-se os dados do quadro 4, nota-se que as vogais do português foram as que obtiveram os menores valores médios para a duração. Todas as vogais analisadas nessa língua são mais curtas do que suas correspondentes em francês e em inglês. Na comparação entre a L2 e a L3 do sujeito, as vogais do inglês que apresentaram os maiores valores foram $/ \varepsilon / \mathrm{e} / \mathrm{i} /$, e as vogais do francês que se mostraram mais longas foram $/ \mathrm{s} / \mathrm{e} / \mathrm{u} /$.

Com a análise dos valores brutos, pode-se apresentar os valores de distância euclidiana calculados para os pares de vogais de línguas diferentes (QUADRO 5). 


\section{QUADRO5}

Distâncias euclidianas entre português/inglês e francês/inglês para duração das vogais produzidas pelo sujeito

\begin{tabular}{l|c|cccc}
\hline & & \multicolumn{2}{|c}{ Português-Inglês } & \multicolumn{2}{c}{ Francês-Inglês } \\
\hline $\begin{array}{l}\text { Distância } \\
\text { Euclidiana }\end{array}$ & $\begin{array}{c}\text { Pares } \\
\text { de vogais }\end{array}$ & $\begin{array}{c}\text { Dist. } \\
\text { Euclidiana }\end{array}$ & $\begin{array}{c}\text { Dist. } \\
\text { Padronizada }\end{array}$ & $\begin{array}{c}\text { Dist. } \\
\text { Euclidiana }\end{array}$ & $\begin{array}{c}\text { Dist } \\
\text { Padronizada }\end{array}$ \\
\hline & $\varepsilon-æ$ & 0,0086 & $7,1 \%$ & 0,0038 & $4,3 \%$ \\
& $\varepsilon-\varepsilon$ & 0,0416 & $34,4 \%$ & 0,0367 & $30,3 \%$ \\
& i - i & 0,0286 & $32,6 \%$ & 0,0278 & $31,7 \%$ \\
& i - I & 0,0082 & $12,2 \%$ & 0,0074 & $11,0 \%$ \\
& u - u & 0,0051 & $9,1 \%$ & 0,0092 & $16,4 \%$ \\
& u - U & 0,0198 & $27,9 \%$ & 0,0054 & $7,7 \%$ \\
& $0-0$ & 0,0098 & $12,6 \%$ & 0,0092 & $11,8 \%$ \\
\hline
\end{tabular}

Ocálculo da distância euclidiana entre português/inglês e francês/inglês aponta que as línguas produzidas com os valores de duração mais próximos foram o francês e o inglês. As durações foram notavelmente mais próximas entre essas línguas para

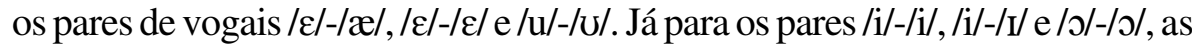
distâncias entre o francês e o inglês foram ligeiramente menores do que as encontradas para o português e o inglês. O único par de vogal comparado que apresentou uma menor distância entre o português e o inglês foi /u/-/u/. Para que se tenha uma ideia mais clara das distâncias entre os pares de vogais comparados entre as línguas, o gráfico seguinte (FIG 5) apresenta as médias obtidas para duração.

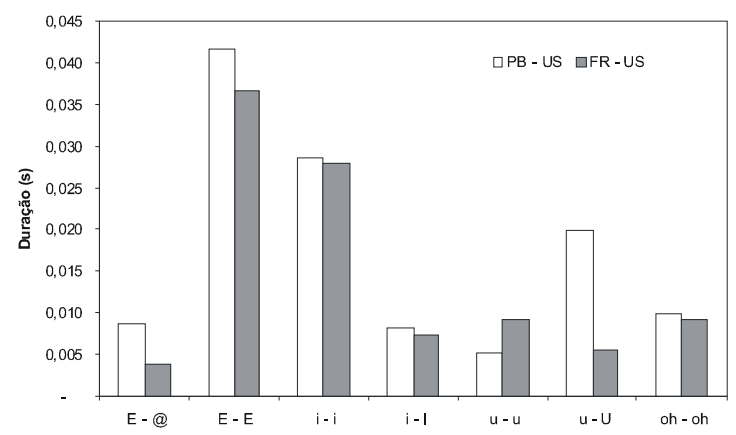

FIGURA 5 - Distâncias euclidianas (duração) entre português/inglês (PB - US) e entre francês/inglês (FR - US) $(E=\varepsilon, @=æ, i=i, l=I, u=u, U=U, o h=0)$ 
Na próxima seção, os resultados ora apresentados poderão ser discutidos de acordo com a fundamentação teórica desenvolvida nesta pesquisa.

\subsection{Discussão dos resultados}

Considerando os resultados descritos para a hipótese desta pesquisa, que previa que a assimilação vocálica durante a tarefa de nomeação de palavras em inglês (L3) ocorreria em direção às características (F1 e F2 e duração) das vogais da L2 do sujeito, pode-se dizer que a hipótese mencionada foi parcialmente confirmada, pois não só a L2 do sujeito influenciou a produção das vogais da L3, mas também a sua L1.

Se forem tomados em conjunto os resultados da análise das distâncias euclidianas de F1 e F2 para os pares de vogais, pode-se notar que houve uma tendência híbrida para a produção da L3, já que a produção nessa língua apresentou características tanto das vogais da L1 quanto da L2 do sujeito. Para as características de F1 e F2, apesar de as distâncias terem sido menores entre o português e o inglês na comparação de quatro pares de vogais (/i/-/I/, /u/-/u/, $/ \varepsilon /-/ æ /, / \varepsilon /-/ \varepsilon /)$, não houve uma mesma tendência para F1 e F2 na comparação dos pares /i/-/i/,/u/-/u/, já que se pôde observar uma maior aproximação entre o francês e o inglês para $\mathrm{F} 1$ e entre o português e o inglês para $\mathrm{F} 2$ nesses pares. $\mathrm{O}$ par $/ \mathrm{J} / \mathrm{/} / \mathrm{/}$, que apresentou uma distância menor entre o francês e o inglês para F2, evidenciou valores semelhantes tanto na comparação entre o português e o inglês quanto na comparação entre o francês e inglês para F1. Dessa forma, nota-se a hibridez na constituição dessa categoria de vogal na língua inglesa do sujeito, já que ela é formada tanto por características da sua L2 (para F1 e F2) quanto da sua L1 (para F1).

Somando-se os resultados encontrados para as distâncias euclidianas de $\mathrm{F} 1$ e F2 entre os pares de vogais com os resultados obtidos na comparação dessas distâncias para duração, a proposição de categorias híbridas para as vogais do inglês produzidas pelo sujeito ganha mais sustentação. Ao contrário do que se observou para as distâncias calculadas para F1 e F2, que apontaram uma tendência mais forte de assimilação vocálica das características do inglês pelo português, os valores encontrados para duração apontaram uma maior semelhança entre o francês e o inglês, já que, dos sete pares de vogais cotejados, seis evidenciaram distâncias menores entre o francês e o inglês produzidos pelo sujeito. Dessa 
forma, pode-se constatar que a análise conjunta das três características observadas nas vogais da língua inglesa (F1, F2 e duração) apontou que nenhuma vogal apresentou todas as suas características assimiladas por apenas uma das línguas previamente adquiridas pelo sujeito.

A proposição defendida por Flege (2002) em suas pesquisas em L2 de que categorias híbridas para a L1 e a L2 seriam formadas quando da impossibilidade de geração de novas, devido a uma grande similaridade entre dois sons de línguas diferentes, também pode ser útil para a explicação dos resultados encontrados nesta pesquisa. Ao levar em consideração a possibilidade de uma tendência híbrida para a produção de sons de dois sistemas distintos, a constatação de Flege (2002) para o campo de L2 pode ser redirecionada para a inclusão, igualmente, da L3 como fazendo parte desse sistema híbrido.

De acordo com Hammarberg (2001), a L2 será notada com mais ênfase na produção de L3 principalmente se um nível elevado de proficiência na $L 2$ for conquistado num ambiente natural de aprendizagem. No caso do sujeito informante deste estudo, apesar de sua proficiência ter sido considerada avançada em francês como L2, seu contato com essa língua ocorreu somente num ambiente formal de ensino, e, desde que concluiu a graduação no curso de LetrasFrancês, sua prática com a L2 vem sendo extremamente limitada. Dessa forma, o alto nível de proficiência constatado na L2, tão somente, não foi suficiente para inibir completamente os efeitos da língua materna do sujeito na sua produção oral em L3. O esperado efeito de recência, apontado pelo mesmo autor como um fator importante para a ativação maciça da L2 no momento da produção em L3, também não pôde entrar em cena com mais ênfase para que o aprendiz de L3 requisitasse mais a $L 2$ do que a $L 1$. Como a $L 2$ não vem sendo ativada pelo sujeito de forma significativa, não ficou tão acessível durante a produção de L3. Assim, não só a L2, mas também a L1 serviram de fonte para a ocorrência da assimilação das características das vogais da L3.

Como a L2 e a L3 do sujeito foram aprendidas no mesmo contexto, isto é, num mesmo ambiente formal de ensino, poder-se-ia esperar um efeito de psicotipologia associando fortemente as duas línguas por esse motivo. Entretanto, ao que parece, o efeito de psicotipologia identificado entre a L2 e a L3 não foi tão forte quanto aquele observado entre a L1 e a L2 do sujeito, já que parece ter havido uma associação mais proeminente entre estas últimas devido ao fato de ambas pertencerem à mesma família linguística, qual seja a das línguas latinas. Levando em consideração o fato de o português e o francês terem criado uma 
forte associação por pertencerem à mesma família linguística, pode-se aventar a possibilidade de o sujeito não ter conseguido estabelecer categorias muito sólidas para os sons da sua L2.

De acordo com o paradigma conexionista, que defende um processamento em paralelo e distribuído para as operações realizadas entre as redes neuroniais, pode-se explicar com excelência a formação das categorias híbridas para a L3 observadas nesta pesquisa. Já que as três línguas estão propensas a serem ativadas simultaneamente pelas redes neuroniais, suas características podem ser misturadas umas às outras, de maneira que esse contato entre elas origine uma produção híbrida na língua menos entrincheirada, tal como pôde ser observado para a L3 envolvida neste estudo, o inglês.

Mais uma vez, pode-se citar Flege (2002) para dar suporte à proposição de categorias híbridas na L3, pois esse autor defende, com base em seus estudos na área da fonética, uma ampla interação entre os sistemas fonéticos dos bilíngues, não sendo possível a destituição de algum desses sistemas no momento da produção oral numa das línguas aprendidas. Em conformidade com esse posicionamento, acredita-se que as características da L1 e da L2 do sujeito foram transferidas de forma equilibrada para a sua $\mathrm{L} 3$, compreendendo a relação entre as três línguas de acordo com um continuum de aproximações que se encaminham em direção aos sons foneticamente esperados para a L3 (FLEGE, 1980). A ideia adotada por esta pesquisa sobre a relação entre fonética e fonologia também pode ser mobilizada para alicerçar a proposição de categorias híbridas na L3, já que também se imagina a existência de um continuum entre a percepção e a produção do sujeito para as línguas que ele conhece. Esse continuum pôde ser evidenciado através das distâncias calculadas para as características (F1, F2 e duração) das vogais produzidas pelo sujeito, já que foram encontrados, nas suas produções em L3, indícios tanto da sua L1 quanto da sua L2. As categorias formadas para a L3, então, são consideradas como o produto da gradiência entre as línguas analisadas.

\section{Considerações finais}

Ao pesquisar o modo como as línguas previamente adquiridas podem influenciar a aprendizagem de uma seguinte, constatou-se a formação de categorias híbridas para a L3 do sujeito, ao mesmo tempo em que também foram encontradas evidências de o sujeito estar começando a adquirir as características verificadas nas vogais da L3. Esses resultados estão de acordo com a visão 
conexionista de aquisição de L2 e com a orientação de Flege (2002), na medida em que se acredita na interação entre os conhecimentos linguísticos nas redes neuroniais. Mesmo que características dos sistemas linguísticos previamente adquiridos sempre sejam notadas em algum grau na produção numa nova língua, evidencia-se, com este estudo, a capacidade que o sujeito tem de aprender novos padrões linguísticos.

O fato de não ter sido comprovada uma influência una da L2 do sujeito sobre as características das vogais da sua L3 não desabona a hipótese prevista para esta pesquisa, pois os resultados encontrados mostram uma riqueza muito maior em termos de processos que podem ocorrer quando se trabalha com três sistemas linguísticos. Apesar de ser uma análise complexa e que ensejaria uma possibilidade muito ampla para a confrontação entre os dados obtidos para as três línguas, a opção adotada neste trabalho parece ter cumprido com os propósitos de averiguar em que sentido a assimilação vocálica poderia ocorrer.

\section{Notas}

${ }^{1}$ Neste trabalho, não se faz distinção entre os termos 'língua estrangeira' e 'L2'. também não se faz diferenciação entre os termos 'aquisição' e 'aprendizagem', como propugnado por Krashen (1982). Os termos serão usados de forma intercambiável, com o devido respaldo de Ellis (1994).

${ }^{2}$ Para este trabalho, o conhecimento fonético-fonológico de uma língua é entendido como a integração entre o conhecimento a respeito da percepção e da produção dos sons da fala. Assim, em conformidade com Albano (2001), não se faz uma distinção categórica e estanque entre fonética e fonologia.

${ }^{3}$ As medidas acústicas $\mathrm{F} 1$ e $\mathrm{F} 2$ referem-se aos dois primeiros formantes do trato vocal. Um formante é um modo natural de vibração (ressonância) do trato vocal. Também pode ser tratado por frequência de ressonância. A frequência de F1 é inversamente relacionada à altura da língua. Já a de F2 é diretamente relacionada ao avanço da língua no sentido anteroposterior.

${ }^{4}$ Zimmer e Alves (2006, p. 113) esclarecem que o entrincheiramento pode ser explicado pelo fato de os aprendizes adultos de uma L2 apresentarem sistemas cognitivos largamente empregados na resolução de outros problemas - incluindo, em particular, a compreensão e a produção de língua materna. A criança, por sua vez, provavelmente alcança um melhor desempenho porque seu sistema cognitivo não está, ainda, totalmente entrincheirado no conhecimento da L1.

${ }^{5}$ As palavras utilizadas nos três experimentos encontram-se em anexas a este artigo. 


\section{Referências}

ALBANO, E. C. O gesto e suas bordas: esboço de fonologia acústico-articulatória do português brasileiro. Campinas: Mercado de Letras, ALB, FAPESP, 2001.

BATES, E. Plasticity, localization and language development. In: BROMAN, S.; FLETCHER, J. M. (Ed.). The changing nervous system: Neurobehavioral consequences of early brain disorders. New York: Oxford University Press, 1999. p. 214-253.

CENOZ, J. Research on multilingual acquisition. In: CENOZ, J.; JESSNER, U. (Ed.). English in Europe. The acquisition of a third language. Clevedon: Multilingual Matters, 2000. p. 39-53.

CHOMSKY, N. Aspects of theory of syntax. Cambridge, Mass: MIT Press, 1965. de BOT, K. The multilingual lexicon: modelling selection and control. International Journal of Multilingualism, v. 1, n. 1, p. 17-32, 2004.

ELLIS, R. The study of second language acquisition. Oxford: OUP, 1994.

FLEGE, J. E. Phonetic approximation in second language acquisition. Language Learning, v. 30, n. 1, p. 117-134, 1980.

FLEGE, J. E. Second language speech learning: Theory, findings and problems. In: STRANGE, W. (Ed.). Speech perception and linguistic experience: Theoretical and methodological issues. Timonium, MD: York Press, 1995. p. 233-277.

FLEGE, J. E. Interactions between the native and second-language phonetic systems. In: BURMEISTER, P.; PIRSKE, T.; RHODE, A. (Ed.) An integrated view of language development: papers in honor of Henning Wode. Trier: Wissenschaftliger Verlag, 2002. p. 217-243.

HAMMARBERG, B. Roles of L1 and L2 in L3 production and acquisition. In: CENOZ, J.; HUFEISEN, B.; JESSNER, U. (Ed.). Cross-linguistic influence in third language acquisition: Psycholinguistic Perspectives. Clevedon: Multilingual Matters, 2001. p. 21-41.

JARED, D.; KROLL, J. Do bilinguals activate phonological representations in one or both of their languages when naming words? Journal of Memory and Language, v. 44, p.2-31, 2001.

JENKINS, J. The role of transfer in determining the phonological core. In:

(Ed.). The phonology of English as an international language: new models, new norms, new goals. Oxford: OUP, 2001. p. 99-119.

KELLERMAN, E. Now you see it, now you don't. In: GASS, S.; SELINKER, L. (Ed.). Language transfer in language learning. Massachusetts: Newbury House Plublishers, 1983. p. 112-134.

MacWHINNEY, B. Language Emergence. In: BURMEISTER, P., PISKE, T.; 
RHODE, A. An integrated view of language development. Papers in honor of Henning Wode. Trier: Wissenchaftliche Verlag, 2002. p. 17-42.

MCCLELLAND, J. L.; MCNAUGHTON, B. L.; O'REILLY, R. C. Why there are complementary learning systems in the hippocampus and neocortex: insights from the successes and failures of connectionist models of learning and memory. Psychological Review, v. 102, n. 3, p. 419-457, 1995.

RINGBOM, H. The role of the first language in foreign language learning. Clevedon: Multilingual Matters, 1987.

RUMELHART, D. E.; MCCLELLAND, J. L. Parallel distributed processing: Explorations in the microstucture of cognition. Cambridgge: MIT Press, 1986.

SEIDENBERG, M.; McCLELLAND, J.; ZEVIN, J. Connectionist Models in Developmental Cognitive Neuroscience: critical periods and the paradox of success. In: MUNAKATA, Y; JOHNSON, M. (Ed.). Attention \& Performance XXI: Processes of Change in Brain and Cognitive Development. Oxford: Oxford University Press, 2006.

SIKOGUKIRA, M. Influence of languages other than the L1 on a foreign language: a case of transfer from L2 to L3. Edinburgh working papers in Applied Linguistics, v. 4, p. 110-132. 1993.

WILLIAMS, S.; HAMMARBERG, B. Language switches in L3 production: implications for a Polyglot Speaking Model. Applied Linguistics, v. 19, p. 295-333. 1998.

ZIMMER, M. C. A transferência do conhecimento fonético-fonológico do português brasileiro (L1) para o inglês (L2) na recodificação leitora: uma abordagem conexionista. 2004. Tese (Doutorado). Porto Alegre: PUCRS, 2004.

ZIMMER, M. C.; ALVES, U. K. A produção de aspectos fonético-fonológicos da segunda língua: instrução explícita e conexionismo. Revista Linguagem \& Ensino, v. 9, n. 2, p. 101-143, 2006.

ZIMMER, M. C.; BION, R. Vowel Assimilation from Brazilian Portuguese (L1) into North-American English (L2) in naming tasks: a connectionist approach to interphonology. In: New Sounds 2007 - Fith International Symposium on the Acquisition of Second Language Speech, 2007, Florianópólis. New Sounds 2007 Conference Program and Abstract Book, 2007. p. 16.

ZIMMER, M. C.; ALVES, U. K; SILVEIRA, R. A aprendizagem de L2 como processo cognitivo: a interação entre conhecimento explícito e implícito. Nonada, v. 9 , p. $157-174.2006$. 


\section{Anexos}

\section{Palavras utilizadas nos testes de recodificação leitora}

\begin{tabular}{|c|c|c|}
\hline Palavras em português & Palavras em francês & Palavras em inglês \\
\hline $\begin{array}{c}\text { data } \\
\text { bata } \\
\text { rata } \\
\text { pata } \\
\text { seta } \\
\text { teto } \\
\text { beta } \\
\text { reta } \\
\text { bêta } \\
\text { teta } \\
\text { chupeta } \\
\text { preta } \\
\text { cota } \\
\text { rota } \\
\text { vota } \\
\text { gota } \\
\text { boto } \\
\text { roto } \\
\text { côto } \\
\text { sita } \\
\text { brita } \\
\text { Rita } \\
\text { fita } \\
\text { libra } \\
\text { escuta } \\
\text { puta } \\
\text { bruta } \\
\text { fruta }\end{array}$ & $\begin{array}{c}\text { robe } \\
\text { sale } \\
\text { pied } \\
\text { pape } \\
\text { Chaise } \\
\text { sept } \\
\text { fait } \\
\text { Chaud } \\
\text { mode } \\
\text { dix } \\
\text { Rouge } \\
\text { rire }\end{array}$ & $\begin{array}{c}\text { fact } \\
\text { with } \\
\text { see } \\
\text { foot } \\
\text { does } \\
\text { put } \\
\text { slip } \\
\text { bus } \\
\text { peel } \\
\text { deed } \\
\text { spook } \\
\text { doll } \\
\text { pear } \\
\text { the } \\
\text { stop }\end{array}$ \\
\hline
\end{tabular}

